Revista Nacional de

Gerenciamento de Cidades

\title{
Importância da arborização em quintais residenciais: um estudo microclimático em duas residências do bairro Rincão, Mossoró/RN
}

Importance of afforestation in residential backyards: a microclimatic study in two residences in the Neighborhood Rincão, Mossoró/RN

Importancia de la forestación en patios traseros residenciales: un estudio microclimático en dos residencias en el barrio Rincão, Mossoró/RN

Amanda da Mota Araujo

Mestranda em Geografia, UERN, Mossoró/RN, Brasil, amandadamotaaraujo@gmail.com

\author{
Alfredo Marcelo Grigio \\ Professor Doutor, UERN, Mossoró/RN, Brasil \\ alfredogrigio1970@gmail.com \\ Márcia Regina Farias da Silva \\ Professora Doutora, UERN, Mossoró/RN, Brasil \\ mreginafarias@hotmail.com
}

Ana Luiza Bezerra da Costa Saraiva Professora Mestra, UERN, Assú/RN, Brasil ageopesquisadora@hotmail.com 


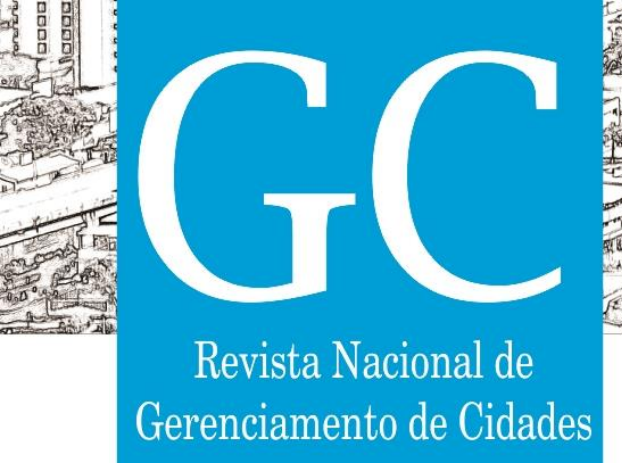

\section{RESUMO}

Este trabalho teve como objetivo verificar o comportamento dos elementos climáticos em quintais residenciais com diferentes padrões de arborização, visando entender a influência que as árvores podem exercer no microclima urbano. Para isto, foram coletados dados de temperatura do ar e umidade relativa do ar em dois quintais residenciais do bairro Rincão, cidade de Mossoró, Rio Grande do Norte (RN). Os dados foram coletados em três dias do mês de novembro, período climático mais quente e seco do ano, e posteriormente foram submetidos ao cálculo do Índice de Calor (IC). Além da coleta de dados climáticos, também foram realizadas entrevistas com uma moradora de cada residência, a fim de compreender a percepção de conforto térmico dos moradores e correlacionar com os dados climáticos coletados em seus respectivos quintais. Ao analisar os dados climáticos coletados, verificou-se que o quintal sombreado R01 registrou menores temperaturas e maiores teores de umidade em relação ao quintal R02, cuja maior parte de sua área é exposta a radiação solar. Quanto ao IC, apesar do quintal R01 apresentar melhores valores em relação ao quintal R02, observou-se a necessidade de pesquisas posteriores que objetivem a criação de índices de conforto/desconforto térmico que sejam mais condizentes com o clima semiárido. Analisando as respostas das entrevistadas ficou nítido o quanto o calor pode afetar negativamente a rotina das pessoas até mesmo dentro de suas residências. Os resultados encontrados demonstram a relevância da arborização urbana para a regulação climática das cidades e, consequentemente, melhoria da qualidade de vida dos citadinos.

PALAVRAS-CHAVE: Arborização Urbana. Conforto Térmico Humano. Saúde Humana.

\section{SUMMARY}

This work aimed to verify the behavior of climatic elements in residential backyards with different afforestation patterns, aiming to understand the influence that trees can exert on urban microclimate. For this, data on air temperature and relative humidity were collected in two residential backyards of the Neighborhood Rincão, mossoró city, Rio Grande do Norte (RN). Data were collected on three days of November, the hottest and drier climatic period of the year, and were subsequently submitted to the calculation of the Heat Index $(\mathrm{CI})$. In addition to the collection of climatic data, interviews were also conducted with a resident of each residence, in order to understand the perception of thermal comfort of residents and correlate with the climatic data collected in their respective backyards. When analyzing the climatic data collected, it was found that the shaded yard R01 recorded lower temperatures and higher moisture content in relation to the R02 yard, most of which is exposed to solar radiation. Regarding $\mathrm{Cl}$, although the R01 yard presented better values in relation to the R02 yard, we observed the need for further research that objectto the creation of comfort/thermal discomfort indices that are more consistent with the semi-arid climate. Analyzing the interviewees' responses was clear how much heat can negatively affect people's routine even within their homes. The results found demonstrate the relevance of urban afforestation for climate regulation of cities and, consequently, improvement of the quality of life of city dwellers.

KEYWORDS: Urban Afforestation. Human Thermal Comfort. Human Health.

\section{RESUMEN}

Este trabajo tenía como objetivo verificar el comportamiento de los elementos climáticos en patios traseros residenciales con diferentes patrones de forestación, con el objetivo de entender la influencia que los árboles pueden ejercer sobre el microclima urbano. Para ello, se recogieron datos sobre la temperatura del aire y la humedad relativa en dos patios traseros residenciales de la ciudad del Barrio Rócilo, la ciudad del mossoró, Rio Grande do Norte (RN). Los datos se recopilaron los tres días de noviembre, el período climático más caluroso y seco del año, y posteriormente se sometieron al cálculo del índice de calor $(\mathrm{Cl})$. Además de la recopilación de datos climáticos, también se realizaron entrevistas con un residente de cada residencia, con el fin de comprender la percepción del confort térmico de los residentes y correlacionarse con los datos climáticos recogidos en sus respectivos patios traseros. Al analizar los datos climáticos recogidos, se encontró que el patio sombreado R01 registraba temperaturas más bajas y un mayor contenido de humedad en relación con el patio R02, la mayoría de los cuales está expuesto a la radiación solar. En cuanto a $\mathrm{Cl}$, aunque el astillero R01 presentaba mejores valores en relación con el astillero R02, observamos la necesidad de realizar más investigaciones que se opusieran a la creación de índices de confort/incomodidad térmica que sean más consistentes con el clima semiárido. Analizar las respuestas de los entrevistados fue claro cuánto calor puede afectar negativamente la rutina de las personas incluso dentro de sus hogares. Los resultados encontrados demuestran la relevancia de la forestación urbana para la regulación climática de las ciudades y, en consecuencia, la mejora de la calidad de vida de los habitantes de las ciudades.

PALABRAS CLAVE: Forestación Urbana. Confort térmico humano. Salud Humana. 


\section{Revista Nacional de Gerenciamento de Cidades}

domiciliar faz parte do cotidiano das pessoas e influenciam na qualidade de vida dos moradores, desta forma, se mostrando como um importante objeto de análise.

\section{METODOLOGIA}

Conforme o Instituto Brasileiro De Geografia e Estatística (IBGE) o município de Mossoró/RN possui uma área territorial de $2.100 \mathrm{Km}^{2}$, sendo que $52,83 \mathrm{~km}^{2}$ são de zona urbanizável e $60,33 \mathrm{Km}^{2}$ de perímetro urbano, com uma população estimada para 2018 de 294.076 mil habitantes. Limita-se com os municípios de Tibau, Grossos, Areia Branca, Serra do Mel, Açu, Upanema, Governador Dix-Sept Rosado e Baraúna (PREFEITURA DE MOSSORÓ, 2010; IBGE, 2010; IBGE, 2018) (FIGURA 1).

Mossoró está inserido na região semiárida do país, cujas características climáticas marcantes são: altas temperaturas e chuvas mal distribuídas no espaço e no tempo. A estação do ano outono (entre março e maio) caracteriza-se por ser mais chuvosa e a estação do ano primavera (entre setembro e novembro) caracteriza-se por ser mais quente e seco (MENDONÇA; DANNI-OLIVEIRA, 2007, SARAIVA, 2014).

Para o presente artigo foram estudados dois quintais residenciais localizados no bairro Rincão. Este bairro está inserido na porção leste da cidade e até o ano de 2010 contava com uma população de 9.631 pessoas, e 3.450 domicílios (IBGE, 2010). Na Figura 1 pode ser visualizada a localização do município, bem como o bairro e os pontos estudados através da coleta de dados.

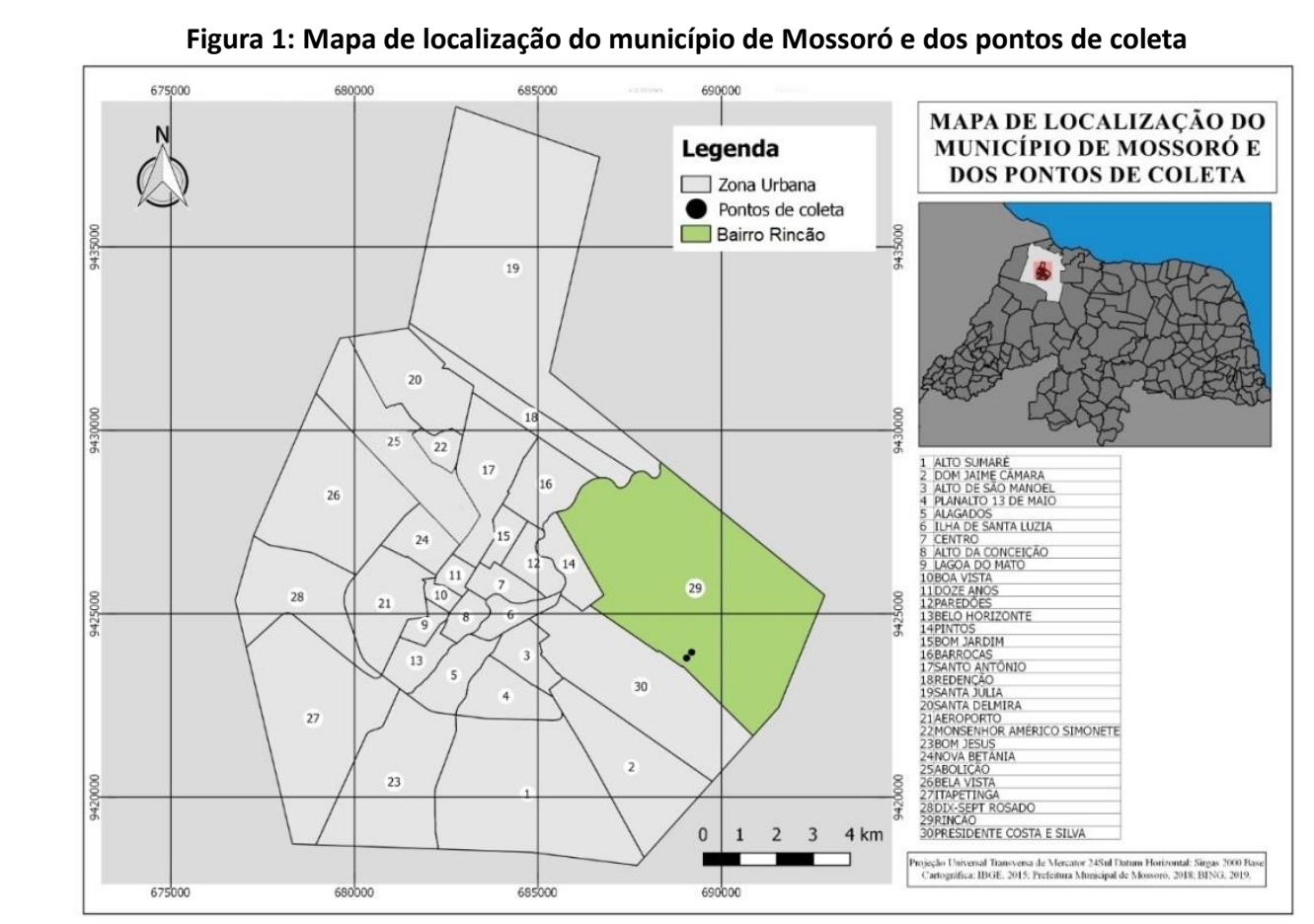

Fonte: IBGE (2015). Prefeitura Municipal de Mossoró (2018). Elaborado por Weslley Misael Bezerra Damasio, 2020. 


\section{Revista Nacional de} Gerenciamento de Cidades

No processo de escolha dos quintais residenciais foram realizadas visitas in loco para realizar uma análise da extensão dos quintais, materiais empregados na sua construção, bem como a existência ou não de árvores de porte arbóreo, em virtude do seu papel termorregulador para o microclima urbano.

A fim de verificar e comparar o comportamento dos elementos climáticos foram escolhidos dois quintais residenciais com diferentes padrões de arborização. A residência denominada como R01 possui um quintal sombreado por árvores de porte arbóreo e frondoso, sendo duas mangueiras (Mangifera indica), uma tamarindeira (Tamarindus indica) e uma laranjeira (Citrus $x$ sinensis), além de plantas ornamentais. Sua extensão é de $260,63 \mathrm{~m}^{2}$ compreendendo a área lateral, frontal e atrás da casa. O solo desse quintal é exposto (FIGURA 2).

Enquanto que na residência denominada como R02 possui duas árvores de porte arbustivo, sendo uma aceroleira (Malpighia glabra) e um limoeiro (Citrus limon Osbeck), porém a maior parte do quintal fica exposta a radiação solar direta. Sua extensão é $161,25 \mathrm{~m}^{2}$, compreendendo a área lateral, frontal e atrás da casa (FIGURA 3). A maior parte do quintal apresenta solo exposto, mas como se pode ver na Figura 3 parte do solo é coberto por vegetação rasteira.

Na Figura 2 observa-se o abrigo meteorológico acomodado embaixo da sombra do limoeiro, localizado na área do quintal que fica na lateral da residência. Já na Figura 3 observa-se o abrigo meteorológico acomodado na área do quintal que fica atrás da residência, onde se recebe intensa radiação solar, entretanto, na imagem o abrigo está sob a sombra, pois a foto foi tirada próximo das $17 \mathrm{hrs}$ da tarde. As residências são localizadas na mesma rua tendo uma distância aproximada de 13 metros como mostra a Figura 4.

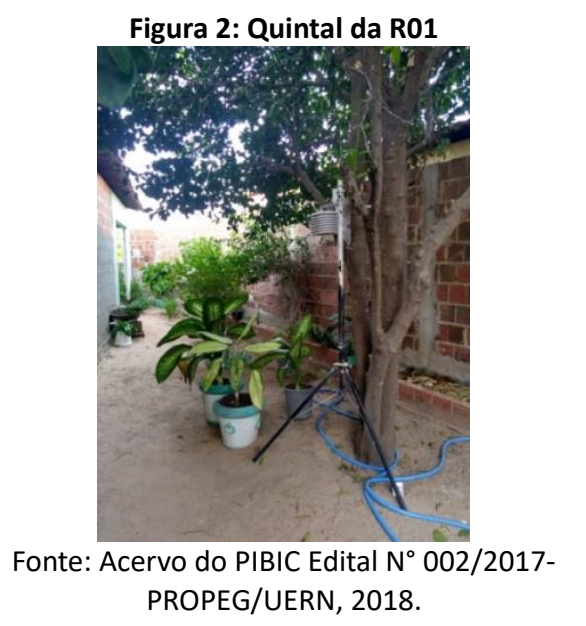

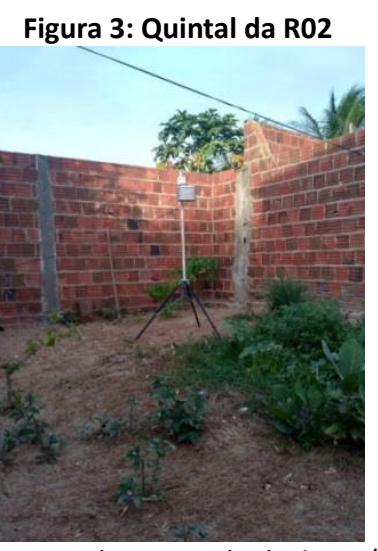

Fonte: Acervo do PIBIC Edital Nº02/2017PROPEG/UERN, 2018. 


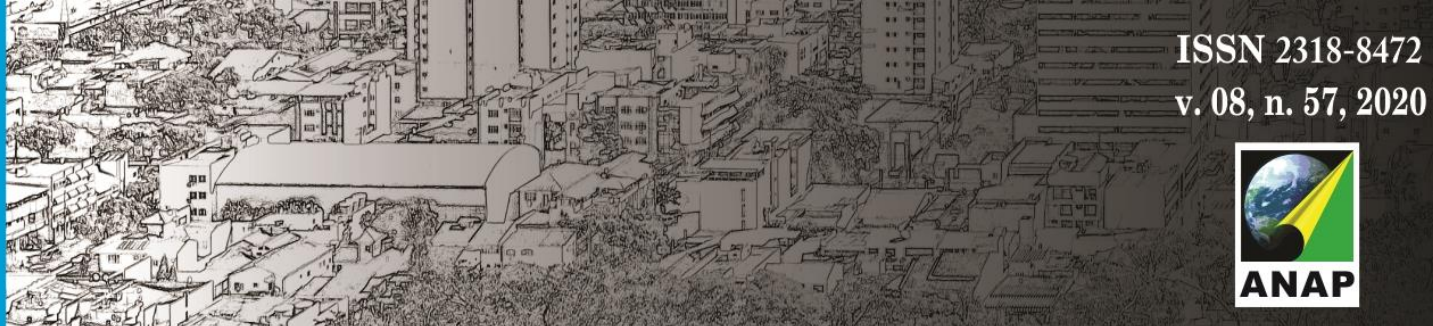

\section{Revista Nacional de}

Gerenciamento de Cidades

do período climático mais quente e seco do ano, onde são registradas as mais altas temperaturas com os menores valores de precipitação e nebulosidade.

A escolha do mês teve como finalidade verificar a atuação das árvores no microclima do quintal da R01 em um período climático que favorece ainda mais o desconforto térmico humano. 0 recorte horário se dá pelo fato de serem as horas do dia de maior aquecimento, possibilitando comparar o comportamento dos elementos climáticos nesses quintais.

Os dados climáticos coletados foram posteriormente submetidos à fórmula do Índice de Calor (IC) da National Weather Service (NWS) e National Oceanic and Atmospheric Administration (NOAA). Este índice estima a intensidade de calor sentida no corpo humano quando submetido a determinados valores de temperatura do ar e umidade relativa do ar (NWS; NOAA, 2011). 0 índice estabelece níveis de alertas e os respectivos sintomas fisiológicos que podem acarretar sobre o corpo humano (FIGURA 7).

Figura 7: Classificação do Índice de Calor e os respectivos efeitos sobre o corpo humano

\begin{tabular}{|c|c|c|c|}
\hline Classificação & IC & Possíveis efeitos sobre o corpo & $\begin{array}{c}\text { Cores } \\
\text { correspondentes }\end{array}$ \\
\hline Cuidado & 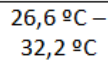 & $\begin{array}{l}\text { Possível fadiga com a exposição } \\
\text { prolongada e ou/ atividade física }\end{array}$ & \\
\hline Extrema cautela & $\begin{array}{c}32,3 \circ \mathrm{O}-\mathrm{C} \\
39,4 \stackrel{\circ}{ } \mathrm{C}\end{array}$ & $\begin{array}{l}\text { Possível insolação câimbras ou } \\
\text { exaustão com a exposição } \\
\text { prolongada e ou/ atividade física }\end{array}$ & \\
\hline Perigo & $\begin{array}{l}39,5 \circ \mathrm{O} \mathrm{C}- \\
51,1 \stackrel{\circ}{ } \mathrm{C}\end{array}$ & $\begin{array}{l}\text { Possível insolação câimbras ou } \\
\text { exaustão com a exposição } \\
\text { prolongada e ou/ atividade física }\end{array}$ & \\
\hline Extremo perigo & $>51,2 \stackrel{\circ}{\mathrm{C}}$ & Insolação altamente provável & \\
\hline
\end{tabular}

Fonte: NWS; NOAA (2011). Tradução nossa. Adaptado pelos autores, 2020.

Além da coleta de dados climáticos nos quintais também foram realizadas entrevistas com uma moradora da Residência 1 (R01) e uma moradora da Residência 2 (R02). 0 objetivo das entrevistas era entender a percepção dos moradores quanto às questões de conforto térmico, desta forma, correlacionando com os dados encontrados em seus respectivos quintais.

O presente artigo é um recorte da pesquisa de dissertação de Araujo (2020) que tem como título "A importância da arborização em quintais residenciais para o conforto térmico em áreas urbanas: um estudo na cidade de Mossoró/RN". A referida pesquisa foi submetida à avalição do Comitê de Ética em Pesquisa (CEP) da UERN, portanto, somente após avaliação e aprovação do CEP/UERN as entrevistas foram aplicadas (Número do Parecer Consubstanciado do CEP: 2.893.903).

Conforme a resolução $n$. 466/12 todo e qualquer projeto de pesquisa que envolva os seres humanos deve ser submetido à apreciação ética de um CEP, objetivando garantir o respeito aos direitos e deveres, assim como, a liberdade, dignidade e autonomia dos participantes (BRASIL, 2012).

Importante destacar também que nas etapas de metodologia da pesquisa de dissertação supracitada houve auxílio do projeto de pesquisa "Elementos climáticos, conforto térmico e vegetação em residências da área urbana de Mossoró/RN" Edital no 002/2017 do Programa Institucional de Bolsas de Iniciação Científica (PIBIC) da UERN, Edição 2018/2019. 


\section{Revista Nacional de}

Gerenciamento de Cidades

\section{RESULTADOS E DISCUSSÕES}

\subsection{Temperatura do ar}

A seguir na Figura 8 são apresentados os dados de temperatura do ar coletados nos quintais das $7 \mathrm{hrs}$ às $17 \mathrm{hrs}$ da tarde. Como se observa na Figura 8 as temperaturas mínimas registradas nesse intervalo horário ocorreram às $7 \mathrm{hrs}$ da manhã em ambos os quintais. Já as máximas temperaturas registradas dentro do intervalo horário ocorreram às $12 \mathrm{hrs}$ nos dois quintais.

Figura 8: Dados de temperatura do ar coletados nos quintais da R01 e R02

\begin{tabular}{|c|c|c|c|c|c|c|c|c|c|c|c|}
\hline \multicolumn{12}{|c|}{ DADOS DE TEMPERATURA DO AR } \\
\hline $03 / 11 / 2018$ & $7 \mathrm{~h}$ & $8 \mathrm{~h}$ & 9h & $10 \mathrm{~h}$ & $11 \mathrm{~h}$ & $12 \mathrm{~h}$ & $13 \mathrm{~h}$ & $14 \mathrm{~h}$ & $15 \mathrm{~h}$ & $16 \mathrm{~h}$ & $17 \mathrm{~h}$ \\
\hline R01 & 25,9 & 28,0 & 30,9 & 33,3 & 34,9 & 36,0 & 33,5 & 32,2 & 32,3 & 31,0 & 29,4 \\
\hline R02 & 26,6 & 29,7 & 35,3 & 40,0 & 41,3 & 42,5 & 38,1 & 34,7 & 35,6 & 33,6 & 30,2 \\
\hline Amplitude & 0,7 & 1,7 & 4,4 & 6,7 & 6,4 & 6,5 & 4,6 & 2,5 & 3,3 & 2,6 & 0,8 \\
\hline $04 / 11 / 2018$ & $7 \mathrm{~h}$ & $8 \mathrm{~h}$ & $9 h$ & $10 \mathrm{~h}$ & $11 \mathrm{~h}$ & $12 \mathrm{~h}$ & $13 \mathrm{~h}$ & $14 \mathrm{~h}$ & $15 \mathrm{~h}$ & $16 \mathrm{~h}$ & $17 \mathrm{~h}$ \\
\hline R01 & 26,4 & 27,9 & 29,3 & 31,8 & 33,8 & 35,4 & 34,4 & 33,0 & 31,5 & 30,3 & 28,6 \\
\hline R02 & 27,1 & 29,6 & 31,5 & 36,7 & 40,1 & 43,4 & 40,1 & 38,5 & 35,7 & 33,1 & 29,4 \\
\hline Amplitude & 0,7 & 1,7 & 2,2 & 4,9 & 6,3 & 8,0 & 5,7 & 5,5 & 4,3 & 2,8 & 0,8 \\
\hline $05 / 11 / 2018$ & $7 \mathrm{~h}$ & $8 \mathrm{~h}$ & $9 \mathrm{~h}$ & $10 \mathrm{~h}$ & $11 \mathrm{~h}$ & $12 \mathrm{~h}$ & $13 \mathrm{~h}$ & $14 \mathrm{~h}$ & $15 \mathrm{~h}$ & $16 \mathrm{~h}$ & $17 \mathrm{~h}$ \\
\hline R01 & 26,4 & 28,2 & 30,5 & 32,5 & 34,1 & 34,9 & 34,5 & 32,9 & 31,5 & 29,8 & 28,2 \\
\hline R02 & 26,9 & 30,5 & 35,4 & 39,5 & 40,8 & 43,4 & 42,3 & 39,6 & 36,4 & 32,6 & 29,0 \\
\hline Amplitude & 0,4 & 2,3 & 4,8 & 7,0 & 6,7 & 8,5 & 7,8 & 6,7 & 4,9 & 2,8 & 0,8 \\
\hline
\end{tabular}

Fonte: Dados da Pesquisa, 2018. Elaboração dos autores, 2020.

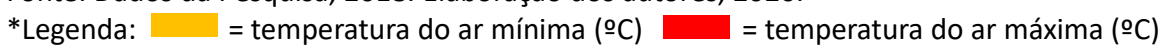

A menor diferença térmica entre os quintais ocorre no horário das $7 \mathrm{hrs}$ e $17 \mathrm{hrs} \mathrm{da}$ tarde. Para as $7 \mathrm{hrs}$ a diferença varia de $0,4^{\circ} \mathrm{C}$ a $0,7^{\circ} \mathrm{C}$ e para as $17 \mathrm{hrs}$ da tarde a diferença térmica é de $0,8^{\circ} \mathrm{C}$. A partir das $7 \mathrm{hrs}$ da manhã se inicia o período de maior aquecimento do dia e às $10 \mathrm{~h}$ da manhã já são encontradas altas temperaturas no quintal R02. No dia 3 de novembro às 10 h registrou-se uma temperatura de $40^{\circ} \mathrm{C}$ no quintal R02 e de $33,3^{\circ} \mathrm{C}$ no quintal R01, sendo uma amplitude térmica de $6,7{ }^{\circ} \mathrm{C}$, assim como nos outros dois dias para esse mesmo horário que a diferença térmica variou de $4,99 \mathrm{C}$ no dia 4 de novembro e 7 으 $\mathrm{C}$ no dia 5 de novembro.

As altas temperaturas continuam até umas $15 \mathrm{hrs}$ da tarde, no qual às $12 \mathrm{hrs}$ são registradas as maiores temperaturas para ambos os quintais e também as maiores diferenças térmicas como se observa no dia 4 de novembro onde a diferença térmica chega a 8 ㄷ $\mathrm{C}$ e no dia 5 de novembro chega a 8,5ํ C. O quintal R02 registrou temperaturas extremamente elevadas e a exposição a ambientes quentes pode acarretar uma série de patologias. Segundo Araújo $(2012$, p. 55) "a intensidade das doenças provocadas pelo calor varia de leves (exantema cutâneo, síncope, cãibras) a graves (exaustão, lesões, choque térmico ou insolação)".

O sombreamento proporcionado pelas árvores presentes no quintal R01 atenuaram as temperaturas em todos os horários e dias estudados. De acordo com Freitas, Santos e Lima (2015) o sombreamento juntamente com a evapotranspiração das árvores são as principais estratégias para o controle da 


\section{Revista Nacional de}

Gerenciamento de Cidades

radiação solar, onde as temperaturas de superfícies dos objetos sombreados são reduzidas e, consequentemente, os teores de umidade relativa do ar aumentam.

\subsection{Umidade relativa do ar}

$\mathrm{Na}$ figura 9 são encontrados os maiores teores de umidade relativa do ar no quintal R01. Para o dia 3 de novembro a diferença higrométrica entre os quintais varia de 2,5\% às 7 hrs da manhã até $9,4 \%$ às $10 \mathrm{hrs}$ da manhã. No dia 4 de novembro a diferença varia de $1,5 \%$ às $7 \mathrm{hrs}$ da manhã até $10,4 \%$ às $12 \mathrm{hrs} \mathrm{da}$ tarde. Por fim, no dia 5 de novembro a diferença higrométrica entre os quintais varia de $1,2 \%$ às $7 \mathrm{hrs}$ da manhã até $12,8 \%$ às $14 \mathrm{hrs}$ da tarde.

Figura 9: Dados de umidade relativa do ar coletados nos quintais da R01 e R02

\begin{tabular}{|c|c|c|c|c|c|c|c|c|c|c|c|}
\hline \multicolumn{12}{|c|}{ DADOS DE UMIDADE RELATIVA DO AR } \\
\hline $03 / 11 / 2018$ & $7 \mathrm{~h}$ & $8 \mathrm{~h}$ & $9 \mathrm{~h}$ & $10 \mathrm{~h}$ & $11 \mathrm{~h}$ & $12 \mathrm{~h}$ & 13h & $14 \mathrm{~h}$ & $15 \mathrm{~h}$ & $16 \mathrm{~h}$ & $17 \mathrm{~h}$ \\
\hline R01 & 77,0 & 66,4 & 56,1 & 48,9 & 45,1 & 43,0 & 58,5 & 62,6 & 62,9 & 66,6 & 70,8 \\
\hline R02 & 74,5 & 61,6 & 47,8 & 39,6 & 36,8 & 34,7 & 49,3 & 55,3 & 54,3 & 58,5 & 66,6 \\
\hline Amplitude & 2,5 & 4,9 & 8,3 & 9,4 & 8,3 & 8,3 & 9,2 & 7,3 & 8,6 & 8,1 & 4,2 \\
\hline $04 / 11 / 2018$ & $7 \mathrm{~h}$ & $8 \mathrm{~h}$ & $9 h$ & $10 \mathrm{~h}$ & $11 \mathrm{~h}$ & $12 \mathrm{~h}$ & $13 \mathrm{~h}$ & $14 \mathrm{~h}$ & $15 \mathrm{~h}$ & $16 \mathrm{~h}$ & $17 \mathrm{~h}$ \\
\hline R01 & 75,2 & 69,0 & 62,6 & 54,2 & 48,2 & 44,9 & 51,9 & 55,1 & 60,6 & 64,3 & 70,3 \\
\hline R02 & 73,7 & 64,3 & 56,2 & 45,7 & 39,2 & 34,5 & 42,5 & 44,8 & 50,2 & 56,1 & 66,1 \\
\hline Amplitude & 1,5 & 4,8 & 6,4 & 8,5 & 8,9 & 10,4 & 9,4 & 10,2 & 10,3 & 8,2 & 4,1 \\
\hline $05 / 11 / 2018$ & 7h & $8 \mathrm{~h}$ & $9 \mathrm{~h}$ & $10 \mathrm{~h}$ & $11 \mathrm{~h}$ & $12 \mathrm{~h}$ & 13h & 14h & 15h & $16 \mathrm{~h}$ & $17 \mathrm{~h}$ \\
\hline R01 & 71,8 & 64,9 & 58,1 & 54,8 & 50,4 & 50,4 & 52,6 & 57,6 & 62,6 & 66,7 & 73,1 \\
\hline R02 & 70,6 & 59,4 & 49,0 & 43,9 & 40,5 & 39,3 & 40,6 & 44,8 & 50,4 & 57,9 & 68,6 \\
\hline Amplitude & 1,2 & 5,4 & 9,1 & 10,9 & 9,9 & 11,2 & 12,0 & 12,8 & 12,1 & 8,8 & 4,5 \\
\hline
\end{tabular}

Fonte: Dados da Pesquisa, 2018. Elaboração dos autores, 2020.

*Legenda: — = umidade relativa do ar mínima (\%) _ = umidade relativa do ar máxima (\%)

Os teores máximos de umidade relativa do ar foram registrados às 7 hrs da manhã em ambos os quintais com exceção do dia 5 de novembro em que o maior teor de umidade do R01 foi encontrado às $17 \mathrm{hrs}$ da tarde. Já os teores mínimos de umidade foram encontrados entre as $11 \mathrm{hrs}$ e $12 \mathrm{hrs}$ da tarde.

Segundo a Organização Mundial de Saúde (OMS) o recomendado para a saúde humana são teores de umidade relativa do ar acima de $60 \%$, já os teores abaixo desse valor e mais especificamente abaixo de $30 \%$ são considerados os mais críticos (OMS, [2012?] apud CENTRO DE GERENCIAMENTO DE EMERGÊNCIAS, 2012).

Os teores acima de $60 \%$ registrados no quintal R01 ocorrem entre $7 \mathrm{hrs}$ e $9 \mathrm{hrs}$ da manhã e $14 \mathrm{hrs}$ às $17 \mathrm{hrs}$ da tarde. Já no quintal R02 ocorrem entre $7 \mathrm{hrs}$ e $8 \mathrm{hrs}$ da manhã e para o horário da tarde somente às $17 \mathrm{hrs}$. Desta forma, os teores de umidade recomendados a saúde são mais frequentes no quintal R01, inclusive, em horários onde ainda há alta incidência de radiação solar como às $14 \mathrm{hrs} \mathrm{e} 15 \mathrm{hrs}$ da tarde.

Ressalta-se que a coleta ocorreu no período climático mais quente e seco e, portanto, são comuns os baixos teores de umidade relativa do ar, principalmente nos horários de maior aquecimento do dia. 
Na pesquisa de dissertação realizada por Saraiva (2014), a autora estudou o clima urbano de Mossoró no ano de 2012 e em sua coleta de dados climáticos no mês de outubro, período mais quente e seco do ano, a mesma encontrou baixos teores de umidade relativa do ar, no qual o intervalo horário das $12 \mathrm{hrs}$ às $15 \mathrm{hrs} \mathrm{da}$ tarde só registrou valores não recomendados a saúde.

Apesar do mês de novembro fazer parte do período climático com as mais altas temperaturas e baixos teores de umidade relativa do ar fica nítido que as árvores presentes no quintal R01 desempenham um papel termorregulador, onde as temperaturas são atenuadas e, consequentemente, os teores de umidade aumentam em comparação ao quintal R02.

\section{3 Índice de Calor (IC)}

Quanto ao cálculo do Índice de Calor as classificações encontradas são apresentadas na Figura 10:

Figura 10: Índices de calor em graus Celsius (ㅇ) encontrados nos quintais R01 e R02

\begin{tabular}{|c|c|c|c|c|c|c|c|c|c|c|c|}
\hline \multicolumn{12}{|c|}{ ÍNDICE DE CALOR } \\
\hline $03 / 11 / 2018$ & $7 \mathrm{~h}$ & $8 \mathrm{~h}$ & 9h & $10 \mathrm{~h}$ & $11 \mathrm{~h}$ & $12 \mathrm{~h}$ & $13 \mathrm{~h}$ & $14 \mathrm{~h}$ & $15 \mathrm{~h}$ & $16 \mathrm{~h}$ & $17 \mathrm{~h}$ \\
\hline R01 & 27,3 & 30,2 & 33,7 & 36,7 & 38,6 & 40,2 & 40,1 & 38,3 & 38,7 & 36,6 & 33,7 \\
\hline R02 & 28,4 & 32,6 & 40,4 & 48,0 & 49,6 & 51,2 & 48,4 & 41,9 & 44,1 & 40,4 & 34,7 \\
\hline Amplitude & 1,1 & 2,4 & 6,7 & 11,3 & 11,0 & 11,0 & 8,3 & 3,7 & 5,4 & 3,9 & 0,9 \\
\hline $04 / 11 / 2018$ & 7h & $8 \mathrm{~h}$ & 9h & $10 \mathrm{~h}$ & $11 \mathrm{~h}$ & $12 \mathrm{~h}$ & $13 \mathrm{~h}$ & $14 \mathrm{~h}$ & $15 \mathrm{~h}$ & $16 \mathrm{~h}$ & $17 \mathrm{~h}$ \\
\hline R01 & 28,3 & 30,4 & 31,9 & 35,0 & 37,4 & 39,6 & 40,0 & 37,8 & 36,0 & 34,4 & 31,9 \\
\hline R02 & 29,4 & 32,9 & 34,8 & 43,0 & 48,1 & 53,5 & 50,1 & 47,0 & 42,6 & 38,4 & 32,8 \\
\hline Amplitude & 1,1 & 2,6 & 2,9 & 8,0 & 10,7 & 13,9 & 10,1 & 9,2 & 6,6 & 4,0 & 0,9 \\
\hline $05 / 11 / 2018$ & 7h & $8 \mathrm{~h}$ & 9h & $10 \mathrm{~h}$ & $11 \mathrm{~h}$ & $12 \mathrm{~h}$ & $13 \mathrm{~h}$ & $14 \mathrm{~h}$ & $15 \mathrm{~h}$ & $16 \mathrm{~h}$ & $17 \mathrm{~h}$ \\
\hline R01 & 28,1 & 30,4 & 33,4 & 36,7 & 38,7 & 40,6 & 40,6 & 38,4 & 36,6 & 33,9 & 31,6 \\
\hline R02 & 28,7 & 33,7 & 41,2 & 49,2 & 50,6 & 57,3 & 55,1 & 50,1 & 44,2 & 37,9 & 32,6 \\
\hline Amplitude & 0,7 & 3,3 & 7,7 & 12,5 & 11,9 & 16,7 & 14,5 & 11,8 & 7,7 & 4,0 & 1,0 \\
\hline
\end{tabular}

Fonte: Dados da Pesquisa, 2018. Elaboração dos autores, 2020.

*Legenda: $\quad$ = Cuidado $\square=$ Extrema cautela $\square=$ = Perigo $\square=$ Extremo perigo

Como se verifica na Figura 10 os resultados apresentam classificações de "cuidado" entre as $7 \mathrm{hrs}$ e $9 \mathrm{hrs}$ da manhã em ambos os quintais e às $17 \mathrm{hrs}$ da tarde somente no quintal R01 nos dias $4 \mathrm{e}$ 5 de novembro. Esta categoria varia entre $26,6 \circ \mathrm{C}$ e $32,2{ }^{\circ} \mathrm{C}$, e embora a classificação do IC considere um alerta para o organismo humano, essa categoria é a menos crítica em relação às outras e seus possíveis efeitos são: uma provável fadiga com a exposição prolongada ao calor e/ou atividade física (NWS; NOAA, 2011).

Com o aumento das temperaturas, encontra-se também a categoria "extrema cautela" que varia entre 32,3 ํ $\mathrm{C}$ e $39,4{ }^{\circ} \mathrm{C}$ e seus possíveis efeitos sobre o organismo humano são: uma provável insolação, câimbras ou exaustão com a exposição prolongada ao calor e/ou atividade física (NWS; NOAA, 2011).

Já nos horários de aquecimento máximo é mais frequente a categoria "perigo" que varia entre 39,5 ํ C e 51,1ํC, onde seus possíveis efeitos sobre o organismo humano também são: uma provável insolação, câimbras ou exaustão com a exposição prolongada e ou/ atividade física 


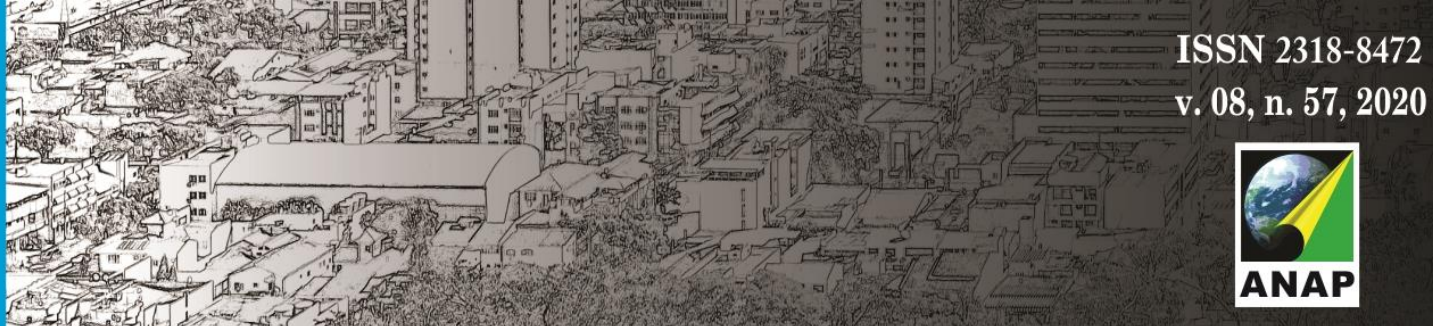

\section{Revista Nacional de}

\subsubsection{Percepção do conforto térmico das moradoras em relação às residências}

As moradoras foram questionadas se se sentiam confortáveis em suas residências ao longo de todo o dia e a moradora da R01 respondeu que se sente confortável a partir das $14 \mathrm{hrs}$ da tarde, pois é mais ventilado. A mesma disse que os horários em que sente mais calor são entre as $9 \mathrm{hrs}$ até $14 \mathrm{hrs}$ da tarde. Já a moradora da R02 respondeu que se sente mais confortável em sua residência pela manhã cedo e fim de tarde. Para ela os horários entre $12 \mathrm{hrs}$ até $14 \mathrm{hrs}$ são os mais quentes do dia.

Como já mencionado o conforto térmico é um conceito subjetivo, pois envolve fatores ambientais e pessoais, sendo assim deve-se levar em consideração não somente os elementos climáticos, mas também a idade, sexo, condições de saúde da pessoa, seu estilo de vida etc. (LAMBERTS, 2016). Uma vez que a sensação de conforto ou desconforto térmico depende de diversos fatores e, isso pode fazer com que alguns indivíduos possam ser mais sensíveis ao calor do que outros. Neste caso em específico, por se tratar de residências, a estrutura das mesmas pode ser favorável ou não para o conforto térmico de seus moradores.

Segundo Santos e Pimentel (2012) alguns dos materiais que são utilizados nas construções de casas são bons condutores de calor o que interferem nas condições térmicas dessas residências. Além dos materiais empregados na construção, é preciso também levar em consideração a posição da residência em relação ao sol, altura da casa, espessura das paredes, bem como tamanho e quantidade de portas e janelas, dentre outros fatores.

Portanto as características das residências e dos quintais influenciam no conforto térmico de seus moradores. Para a moradora da R02 o fato de a maior parte de seu quintal ficar exposta a radiação solar direta pode ser ainda mais agravante, pois ocorre um maior aquecimento de seu quintal e, consequentemente, pode emanar mais calor para dentro de sua residência. De acordo com Gartland (2010) quanto mais frescos estiverem às superfícies dos materiais, menos calor será transmitido.

Ao serem questionadas se sentem sintomas desagradáveis quando estão com calor à moradora da R01 se mostrou bastante sensível, pois a mesma respondeu que em situações de forte calor sente calafrio, mal-estar, sudorese e quando esses sintomas são mais intensos sua pressão chega a subir. Importante destacar que a moradora diz ser hipertensa, assim como seu marido. A entrevistada menciona ainda que para amenizar esses sintomas ela toma banho e logo em seguida faz uso do ventilador para diminuir seu calor. Quando perguntada se o calor atrapalha as suas atividades do dia a dia ela respondeu que sim como, por exemplo, cozinhar em determinados horários e até mesmo arrumar sua casa citando que às vezes precisa pausar e retomar em outro momento.

A moradora da R02 também diz ser hipertensa e, em situações de forte calor sente mal-estar, sensação de agonia e, em determinadas situações sua pressão também sobe. Entretanto, ela diz que no geral não considera que o calor atrapalhe suas atividades do dia a dia. 


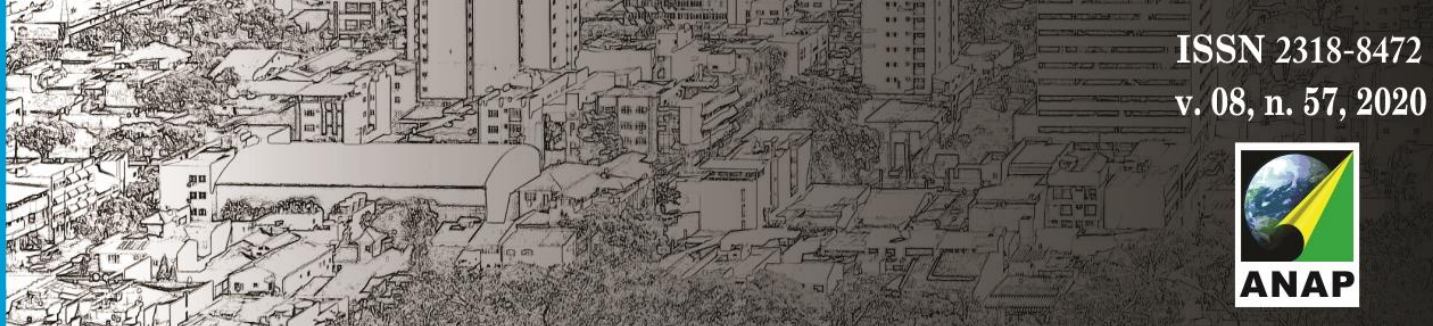

\section{Revista Nacional de}

quintal que fica localizado atrás da residência, pois considera mais ventilado. Quanto ao uso que faz de seu quintal, se limita aos afazeres domésticos, onde dá preferência em realizá-los pela manhã cedo enquanto ainda não está quente. Destaca-se que o quintal da moradora apresenta altas temperaturas a partir das $10 \mathrm{hrs}$ da manhã e somente a partir das $16 \mathrm{hrs}$ as temperaturas diminuem. Entre $11 \mathrm{hrs}$ e $13 \mathrm{hrs}$ da tarde foram registradas temperaturas acima de 40 으.

As entrevistadas também foram questionadas sobre o motivo de seus quintais terem ou não árvores e se as mesmas sentiam alguma relação afetiva para com os quintais. A moradora da R01 respondeu que sempre morou em sítio e que por isso desejava ter um quintal com árvores. No ano em que chegou em sua casa havia somente ervas daninhas em seu quintal, então decidiu plantar árvores frutíferas e plantas ornamentais. Sobre a relação afetiva a mesma respondeu que seu quintal é muito importante e que sua maior satisfação é o momento que dedica ao cuidado de suas plantas, segundo a própria moradora, considera esses momentos como terapêuticos.

Alguns estudos associam atividades de jardinagem, cultivo de plantas e o contato com áreas verdes em geral com a melhoria e qualidade de vida e saúde das pessoas. Em estudo conduzido por Van Der Berg e Custers (2011) concluiu-se que as práticas de jardinagem podem promover o alívio do estresse agudo. Conforme Amato-Lourenço et al. (2016, p. 125):

[...] Proximidade de áreas verdes associa-se a menor obesidade, menor risco de desenvolver doença cardiovascular, menos doenças mentais, melhores desfechos de nascimento, entre outros. Além dos serviços ambientais prestados pelas áreas verdes, acredita-se que o contato com o verde diminua o estresse, aumente a coesão social e o nível de atividade física [...]

A moradora da R02 também respondeu gostar de plantas. Em seu quintal tem uma aceroleira e um limoeiro, segundo ela, apesar de fazer pouca sombra no quintal ela gosta de cuidá-las. A moradora demonstra afetividade para com o seu quintal, mas não faz muito uso dele por justamente ser termicamente desconfortável a maior parte do dia.

\section{CONSIDERAÇÕES FINAIS}

Ao analisar o comportamento dos elementos climáticos nos quintais estudados fica nítido que as árvores presentes no quintal R01 foram fundamentais para atenuar as temperaturas do ar e aumentar os teores de umidade relativa do ar. Esse resultado mostra a importância da arborização urbana para a melhoria do microclima urbano, principalmente para uma cidade de clima semiárido.

Quanto ao Índice de Calor, apesar do quintal R01 apresentar menores valores do IC e uma menor frequência das categorias mais críticas, esse índice não foi desenvolvido para a realidade climática do Semiárido nordestino. Inclusive, se desconhece índices de conforto/desconforto térmico próprios para este clima, o que torna necessárias pesquisas posteriores que 


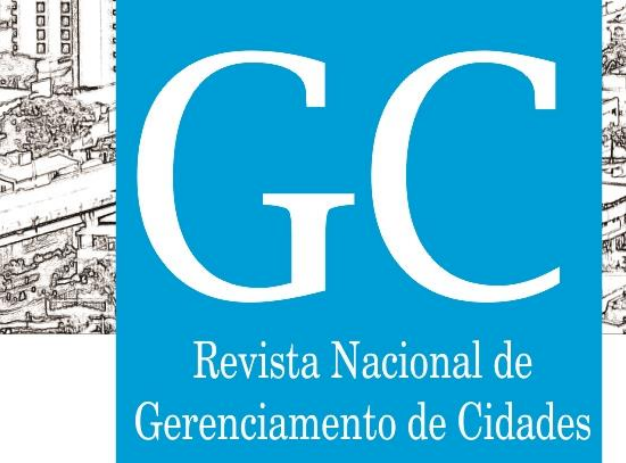

desenvolvam índices condizentes que possam contribuir com os estudos sobre clima e conforto térmico no Semiárido.

A etapa das entrevistas se mostrou relevante para entender a percepção de conforto térmico das moradoras quanto as suas residências e quintais. As respostas das entrevistadas mostraram o quanto o calor pode afetar negativamente a rotina das pessoas até mesmo dentro de suas residências, um local que deveria ser de descanso e lazer.

Quanto aos quintais a presença de árvores e o cultivo de plantas ornamentais, além de melhorarem o microclima, também podem contribuir com a saúde física e mental dos moradores. Como mencionado anteriormente à própria moradora da R01 disse que considera como terapêutico o momento que dedica aos cuidados de suas plantas.

Diante dos resultados apresentados reitera-se a relevância da arborização urbana para a regulação climática das cidades e, consequentemente, melhoria da qualidade de vida dos citadinos, uma vez que o desconforto térmico pode afetar o bem-estar e saúde das pessoas.

\section{REFERÊNCIAS}

AMATO-LOURENÇO, L. F. et al. Metrópoles, cobertura vegetal, áreas verdes e saúde. Estudos Avançados, v. 30, n. 86, p.113-130, 2016.

ARAUJO, R. R. O Conforto térmico e as implicações na saúde: uma abordagem preliminar sobre os seus efeitos na população urbana de São Luís-Maranhão*. Revista cadernos de pesquisa, São Luís-MA v. 19, n. 3, set./dez. 2012.

ARAUJO, A. M. Arborização e conforto térmico humano: um estudo de caso em três praças públicas do centro urbano de Mossoró/RN. 2017. 61 f. Monografia (Bacharelado em Gestão Ambiental) - Universidade do Estado do Rio Grande do Norte, Mossoró, 2017.

ARAUJO, A. M. A importância da arborização em quintais residenciais para o conforto térmico em áreas urbanas: um estudo na cidade de Mossoró/RN. 2020. 111 f. Dissertação (Programa de Pós-Graduação em Geografia) - Universidade do Estado do Rio Grande do Norte, Mossoró, 2020.

BALBUS et al. Introduction: Climate Change and Human Health. The Impacts of Climate Change on Human Health in the United States: A Scientific Assessment. U.S. Global Change Research Program, Washington, DC, 25-42. Ch. 1, 2016.

BEZERRA, L. G. S. Análise microclimática das áreas de convivência do campus central da Universidade Do Estado Do Rio Grande Do Norte: episódio de primavera Mossoró 2019. 2019. 86 f. Monografia (Bacharelado em Gestão Ambiental) - Universidade do Estado do Rio Grande do Norte, Mossoró, 2019.

BRASIL. Ministério da Saúde. Conselho Nacional de Saúde. Resolução n. 466, de 12 de dezembro de 2012. Aprova diretrizes e normas regulamentadoras de pesquisas envolvendo seres humanos. Brasília, Diário Oficial da União, 12 dez. 2012.

CENTRO DE GERENCIAMENTO DE EMERGÊNCIAS. Umidade relativa do ar. São Paulo: CGE, 2012. Disponível em: <https://www.cgesp.org/v3/umidade-relativa-do-ar.jsp> Acesso em: 01 fev. 2019.

FREITAS, A. F. ; SANTOS, J. S. ; LIMA, R. Ba.. Microclima urbano: um estudo de caso no espaço intra-urbano do Campus I da UFPB. Revista Gestão \& Sustentabilidade Ambiental, [S.I.], v. 4, p. 271-287, 2015

GARTLAND, Lisa. Ilhas de calor: como mitigar zonas de calor em áreas urbanas / Lisa Gartland; tradução Silvia Helena Gonçalves. -São Paulo: Oficina de textos, 2010.

GOOGLE EARTH. Google Earth. Brasil: Google Earth, 2018. Disponível em: https://earth.google.com/web/. Acesso em: 03 jan. 2020. 
